\title{
Taking School Athletics Teams on the Road - Is it Worth the Risk?
}

\author{
Brad Madden ${ }^{1}$, Joe Deutsch ${ }^{2 *}$ \\ ${ }^{1}$ Physical Education Teacher, Nido de Aguilas, Santiago, Chile \\ ${ }^{2}$ Associate Professor, Physical Education Pedagogy, North Dakota State University, Fargo, ND, USA \\ *Corresponding Author: Joe Deutsch, Associate Professor, Physical Education Pedagogy, North \\ Dakota State University, Fargo, ND, USA
}

\begin{abstract}
School athletics programs provide students with learning opportunities that contribute to a richer educational experience. Through participation in athletics, students set and reach goals, contribute to their school community in positive ways and learn an abundance of lifelong skills such as teamwork, perseverance, commitment and humility among many others. Students who participate in their school athletics program will often do so after school and on weekends. They will participate in team or individual training sessions and often their school will be a member of an interscholastic league in which local schools compete over the course of a season for a regional championship. In some instances, schools and their respective athletic programs will offer students opportunities to travel with their teammates to compete in a different region, state or even country. This sort of experience offers student athletes an opportunity to test themselves against various levels of competition, develop bonds with teammates that may last a lifetime and provide new opportunities for skill development in both their respective sports and real world skills. However, when deciding to turn a local school sports team into an overnight traveling team, schools, athletic administration and coaching teams must assess the benefits and potential risks involved in assuming responsibility of care for minors and ensure they have established a variety of protocols and expectations that will facilitate a safe and positive experience for everyone involved.
\end{abstract}

\section{BENEFITS OF GOING BEYOND THE SCHOOL AND LOCAL FIELDS}

Taking students off of school property means more is at risk from a legal standpoint, but it is undeniable that learning experiences outside of school walls provide student athletes with a host of benefits that they cannot always gain through interscholastic competition. Some of these benefits include team building, experiencing other cultures, facing new competition, building character, and experiencing the authentic lifestyle of a professional athlete. Away tournaments and competitions afford players and teams extended amounts of time spent on buses, planes and in hotels where they can connect with their teammates. The opportunity to spend time with players away from the pressures of school and life back home can help coaches get to know their players on an individual and more personal level, and allow space for teammates to bond while sharing a unique and lifechanging experience (Rosin, 2018). Relationship building requires time. Traveling to participate with teammates is an experience that naturally builds a team and ultimately the relationship amongst the players on the team. Typically, when teams travel to a new state or country, the sporting event will usually take place over a couple of days. Student athletes learn about other cultures from interacting with players from other schools in between games as well as from traveling from the hotel to field, dining out, or even engaging in some touring activities with their own teammates. These culture-rich experiences are unique to traveling for sports because when athletes participate in a local event, athletes may travel to a rival school, participate in game play, and then head back to their own school or house when the competition is complete. Rosin (2018) also suggests that "playing with and against teams from other cultures can highlight what a particular sport means to a community" (p. 1).

Moreover, student athletes who travel to compete in sporting events have the opportunity to participate in new levels of competition and learn from their opponents. According to Rosin (2018), "whether it's a game of baseball in the Dominican Republic, rugby in Fiji, volleyball in Cambodia, or soccer in Costa Rica, there's a unique opportunity to share strategies from athletes around the world 
who've grown up playing the sport and learn moves that teams can eventually use on their home court" (p. 1). Student athletes who travel for sporting competitions also gain some insight into the life of professional athletes. This style of participation may help them feel more connected to their passion, energize their enthusiasm or participation and provide them with an opportunity for authentic exploration. Traveling for sport also offers students a break from the normal routine, which places many students in the position to work on developing life or character building skills. Having coaching staff or chaperones present ensures that the students remain safe, however being away from parents and teachers means that they are required to be more independent than they may need to be in their daily lives.

\section{What COULd Go Wrong?}

With all the aforementioned benefits of traveling school teams, it is no wonder schools include interstate or international competitions in their athletic programs. However, along with the benefits come substantial risks on the part of the coaches and chaperones. Even some schools can be held responsible if something were to go wrong. Some of these risks include; athletes facing injuries on or around the sporting event, lack of supervision either at the event or during the athletes' downtime, serious illness as a result of travel or travel experiences, and/or an injury that happens during transit at any given time over the course of the trip. In all sports, whether traveling or not, "there are many unfortunate opportunities for players to be harmed in a variety of ways. Often the coach is responsible for the safety of his or her players and can be liable if an accident occurs" (Christofferson\& Deutsch, 2018 , p. 14). Taking a sports team on the road and abroad opens the doors for legal issues beyond common sports injuries that might happen at school. Recently, in the case of Munn vs Hotchkiss (Fay \& Forbes, 2017), a 15 year old student participating in a school-sponsored international excursion suffered severe brain damage and loss of movement as a result of an infectious disease contracted on the trip. The Supreme Court found "unanimously that 1) the state's public policy supports imposing an affirmative duty on schools to warn about and protect against the risk of insect-borne diseases and 2) an award of $\$ 41.5$ million for the breach of that duty fell within the limits of just compensation" (Fay \& Forbes, 2017, p. 1). Ultimately, it is the responsibility of the school, coaches and chaperones to know the potential risks that student athletes face while traveling for sport as well as understanding their role and responsibilities in avoiding negligence, and the potential of a civil, liability suit.

What exactly does it mean to be negligent? "Before a teacher or coach would have to assume financial responsibility for a student's injury, the teacher or coach would have to be found guilty of negligence. In order to be found guilty of negligence, four elements need to exist: duty, breach, cause, and harm. All four elements must be proven in order for negligence to be proven" (Carpenter, 2014, p. 57). The relationship that exists between a teacher and a student or a coach and an athlete legally places the teacher/coach in the position to assume duty of care on behalf of the school and therefore they carry the responsibility for protecting the student/athlete from injury or harm. There are a number of duties in which a coach is responsible and for which they should recognize as their duty, from providing sound developmentally appropriate instruction while ensuring there is adequate supervision to safe use of the environment and equipment (Carpenter, 2014). Acknowledging the various duties present as a result of the relationship is a necessary step in ensuring negligence is avoided, however solely being aware isn't enough. Coaches need to understand that a breach of duty suggests that the duty of care was not met by an acceptable standard. The standard of care ensures that the duty is carried out in a way determined by comparison to what a reasonable person would do. "The law imposes a duty of care upon individuals who are presumed to possess "common sense" to perceive the potential dangers inherent in a given situation and to exercise the same degree of caution as any other individual would in those same circumstances. While the standard is not one of perfection and allows for mistakes and errors of judgment to be made, the reasonable person is cautious by nature and more alert to risk than most people" (Sport Liability Law, 2012, p. 3).

Furthermore, if a breach of duty has occurred, it becomes a question of whether or not the breach caused the injury. The cause of the injury must be satisfied as a required element of negligence claim. An action or even an in-action could potentially impact the result of an injury. "In determining whether causation has been established, the court applies the "but for" test which requires the court to ask "but for" the actions of the defendant, would the plaintiff's injuries have occurred? If the answer is no, then the defendant will be held responsible for the damage" (Sports Liability Law, 2012, p. 6). Finally, when harm is the result of a breach of duty caused by the individual(s) in question a claim of 
negligence can be made. If there is no significant harm than there can be no negligence claim. "Technically, any physical injury fulfills the element of harm. However, the trier of fact (jury) determines if an injury is sufficient to demonstrate that the teacher breached the duty to protect students from the foreseeable risk of unreasonable harm" (Carpenter, 2014, p. 60). In regards to a traveling team, caregivers who do not keep students reasonably safe may be exposing themselves to claims of negligence by parents seeking to obtain compensation for the breach of duty.

\section{STRATEGIES FOR SAFE PLANNING AND IMPLEMENTATION}

Knowing the benefits and the risks involved with taking student athletes off campus and on overnight excursions, it is fair to say that the benefits outweigh the risks considering the number of events attended across the country and the world. Opting to assume the risks in order to reap the benefits is a choice that should be accompanied by a plan of action to avoid unnecessary risk and ensure transparency and a shared understanding of the potential risks involved in the undertaking. It may be helpful to consider looking at creating a plan of action through two lenses; the school level and then the coach or team level.

Schools need to ensure that they are ready for teams to travel by knowing the particulars of their insurance coverage and by ensuring that policies, a code of conduct and the school handbook are developed and up to date. Private schools need to be sure to develop their policies thoroughly and in consultation with legal authorities, as they are governed independently and therefore at greater risk compared to public schools. The school should ensure that these documents are shared amongst all stakeholders prior to departure. Acknowledgement of these guiding documents can be in the form of an Athletics Traveling Team Contract to be signed by student athletes, parents and the head coach. The contract would specifically articulate the consequences for breaching the code of conduct along with the protocols for chaperones to follow when a breach has occurred (Constantinesco, 2015). For example, the contract might outline that in the event of an athlete being under the influence of alcohol, they will be sent home at the expense of the parents. "Students and faculty on these trips are better served by knowing exactly what the disciplinary procedures and consequences will be before they leave campus" (NAIS, 2018). When parents sign the contract and release form, they need to know exactly what their responsibilities and liabilities are in the event of any risk associated with injury, illness, behavior, and travel. Just as in any sort of international travel, schools must encourage parents to purchase travel insurance to cover costs associated with emergencies. If they choose not to, this should also be in writing as part of the release.

Some strategies schools can employ to support team travel are to form a committee and outline a process for reviewing the trip in its entirety. The committee can provide feedback to the head coach for proposed excursions away from the school. Additionally, schools can aim to hire experienced coaches and include questions in their interview process about safety and stakeholder communication for overnight excursions. Research suggests that "coaches are leaving the profession, and coaches with 10 years of experience or less are becoming the majority in the field" (Swanson \& Deutsch, 2017). A study conducted by Swanson \& Deutsch (2017), showed a strong need for mentoring for high school coaches. For a less experienced coach who is taking a team on the road, a mentor can be someone they can talk to about safe planning and difficult situations that may arise before departing or during the trip. Schools can look to implement and support a mentorship program for their growing coaches, so that coaches have the support they need to take a sports team on an overnight excursion.

Understanding and promoting school policy is an essential step for a coach, however their role doesn't stop there. There are a number of things a coach should do in preparation for departure and while away on the trip. Prior to leaving, the coach should consult the Athletic Director and they should compile and review the credentials and contact details of all emergency resources in the area as well as all outsourced suppliers (transportation \& hotels) and ensure they have all the necessary specifics on expectations and terms of use. They should ensure that their travel manual contains emergency contact information for each student and any medical or student specific needs that will require attention on the trip. The school handbook and school code of conduct should be honored and used for consistency on the trip. They must see to it that each student has filled out all the necessary information on their travel form and that information is used to create a quick reference document.

The coach's role is to hold pre-travel mandatory meeting for all participants with parents, studentathletes, chaperones, assistant coaches and school administration representative in attendance. These 
meetings can be done separately, however separate meetings can create an opportunity for miscommunication and gaps in information. Requiring at least one legal guardian to attend will ensure that all pertinent information is provided such as reviewing behavior expectations and consequences, associated risks with travel and participation in competitive physical activity, any government travel advisories regarding the intended location of travel and any transportation risks that may be encountered (i.e. bad weather, common risks of flying using highways or small town roads). Scheduling in time for questions and answers can also be valuable to both the parents and the coach. It is essential that the coach is prepared and well informed in order to field questions in the moment, however providing guardians and student athletes with the opportunity to ask questions offers them a chance to develop a deeper understanding of the travel. Including them in the process, helps the coach to gauge how well the information provided has been received and that questions answered are heard by everyone.

As a disclaimer, it is necessary to acknowledge that, even if the school administration team and coaching staff have been extra prudent in attending to all the aforementioned preparation steps and even if parents and student- athletes have attended the meetings, demonstrate an understanding of the expectations and risks involved in participating in the event, and they have signed their student athlete contracts and legal guardian release forms, the release forms do not fully protect coaches, chaperones and all schools from liability suits and therefore should be considered a precautionary step (Christofferson\& Deutsch, 2017). In the end, the student-athletes in most cases will be minors and according to Daiya (2017), "If any injuries were the result of negligence, no permission slip will absolve a school board or other responsible party from liability. Students are not able to "contract out" of negligence, and are not considered to have assumed any risk of negligence by signing a permission form" (p.1).

Considering all of the risks associated with taking a team on the road, one might wonder why schools would even suggest that their athletes engage in tournaments and competition outside of their school, state or country. In the recent case of the 15 year old who suffered significant damage from the disease she contracted abroad, the school argued that "that imposing a legal duty to warn and protect against insect-borne diseases would discourage participation in such travel" (Fay \& Forbes, 2017, p. 1). This argument was rejected by the Court as they recognized the benefits of travel and suggested that the duty of warning and taking protective measures only promotes the safety of students (Fay \& Forbes, 2017).

Less is not more when it comes to preparing student athletes and their families for overnight excursions. Issues can be avoided thorough preparation and clear communication of roles and responsibilities of each person involved is good practice for safe travel and enjoyment. Just as in all aspects of coaching, a coaches role is to not only teach the sport but to also to model and prepare students for being upstanding members of society. Moreover, by setting an example of consistency and care, coaches have the power to build the culture of the team. If the culture is one of high expectation, leadership and support, student athletes may be more inclined and better prepared to make good decisions around safety and behavior while representing their school, their team, and their family in an unfamiliar location.

\section{REFERENCES}

[1] Carpenter, L. (2014). Legal concepts in sport. Urbana, Illinois: Sagamore Publishing.

[2] Christofferson, J. \& Deutsch, J. (2017). Effective organizational and coaching strategies for youth traveling teams. Strategies, 30(3), 18-22.

[3] Christofferson, J. \& Deutsch, J. (2018). More effective organizational and coaching strategies for youth traveling teams. Strategies, 31(2), 13-18.

[4] Constantinesco, K. (2015). Timeout $Q$ \& A. Bringing your team on the road. Retrieved from http://purpose2play.com/2015/02/27/timeout-qa-bringing-your-team-on-the-road/

[5] Daiya, J. (2017) How school permission forms impact liability. Retrieved from https://jdlawyers.ca/ children-minors/school-permission-forms-impact-liability/

[6] Fay, J. \& Forbes, M. (2017). Connecticut Supreme Court issues decision in Munn vs Hotchkiss. Retrieved from https://www.shipmangoodwin.com

[7] NAIS (2018). Field trip and travel liability: have you limited yours? Washington, DC: National Association of Independent Schools. 
[8] Rosin, E. (2018, January 18). Five benefits of traveling with your team. Retrieved from http://www. rusticpathways.com

[9] Sport Liability Law (2012). A guide for amateur sports organizations and their insurers. Toronto, CA: Dolden Wallace Follick.

[10] Swanson, J. \& Deutsch, J. (2017). Mentoring in sports for the development of the successful high school coach. Journal of Human Sciences, 14(2), 1158-1180.

Citation: Brad Madden, Joe Deutsch. "Taking School Athletics Teams on the Road - Is it Worth the Risk?" International Journal of Sports and Physical Education (IJSPE), vol 5, no. 4, 2019, pp. 23-27. doi: http://dx. doi.org/10.20431/2454-6380.0504004.

Copyright: (C) 2019 Authors. This is an open-access article distributed under the terms of the Creative Commons Attribution License, which permits unrestricted use, distribution, and reproduction in any medium, provided the original author and source are credited. 